Supporting Information

\title{
Inorganic Nanotube Mesophases Enable Strong
}

\section{Self-Healing Fibers}

Won Jun Lee, ${ }^{\dagger \neq}$ Erwan Paineau, ${ }^{\S}$ David Benbow Anthony, ${ }^{\dagger}$ Yulin Gao,,$^{\dagger}$ Hannah Siobhan Leese, ${ }^{\dagger \neq}$ Stéphan Rouzière, ${ }^{\S}$ Pascale Launois, ${ }^{\S}$ and Milo Sebastian Peter Shaffer ${ }^{\dagger 0 *}$

$\dagger$ Department of Chemistry, South Kensington Campus, Imperial College London, London, U.K. SW7 2AZ

$\S$ Laboratoire de Physique des Solides, UMR CNRS 8502, Université Paris Sud, Université Paris Saclay, Bâtiment 510, Orsay, Île-de-France, FR 91405, France

$\diamond$ Department of Materials, South Kensington Campus, Imperial College London, London, U.K. SW7 2AZ

\section{Present Addresses}

$\ddagger$ Department of Fiber System Engineering, Dankook University, Jukjeon, Yongin, Gyeonggido, KR 16890

$¥$ Department of Chemical Engineering, University of Bath, Claverton Down, Somerset, Bath, U.K. BA2 7AY

\section{Corresponding Author}

*E-mail: m.shaffer@imperial.ac.uk. 

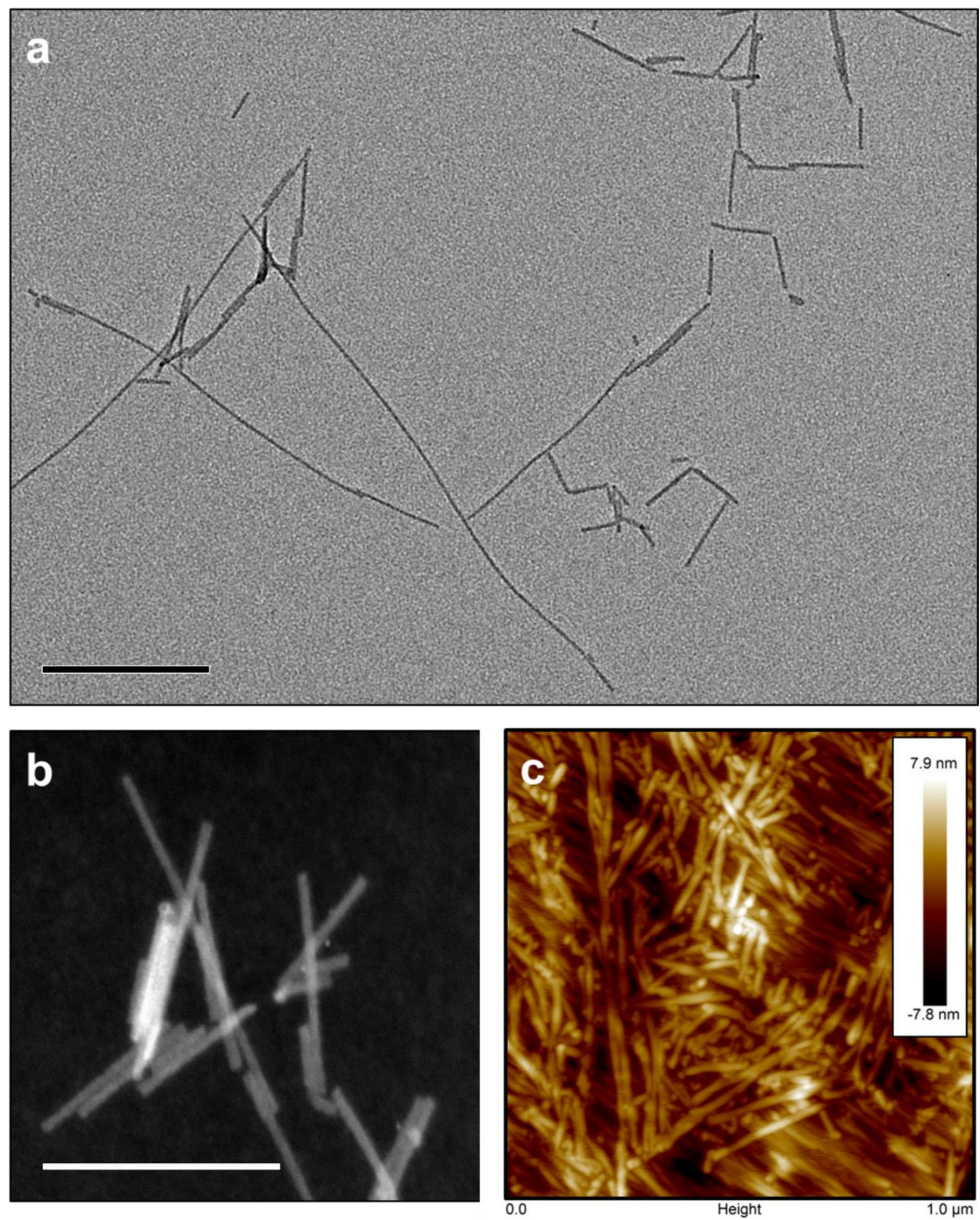

Figure S1 Characterization of synthesized double-walled aluminogermanate imogolite nanotubes, (a) transmission electron micrograph (TEM) image with $200 \mathrm{~nm}$ scale bar, (b) higher magnification scanning TEM high-angle annular dark-field image with $100 \mathrm{~nm}$ scale bar, (c) atomic force microscopy box size $1 \mu \mathrm{m} \times 1 \mu \mathrm{m}$. 
Optical microscopy of double-walled aluminogermanate imogolite nanotube spinning dopes
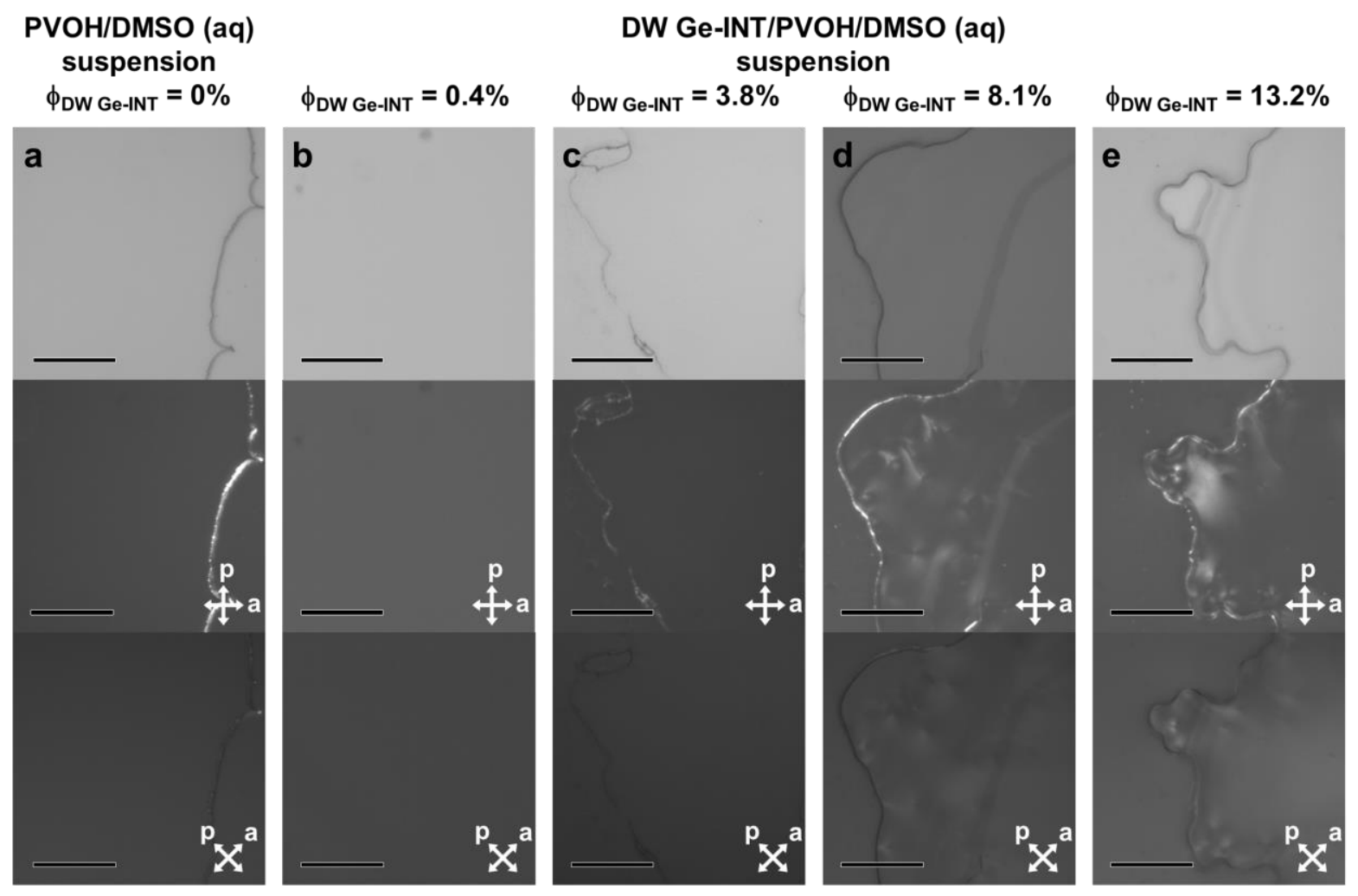

Figure S2 Grayscale transmission optical micrographs of a range of spinning dopes, without polarizers (top) and with cross-polarizers (middle $0^{\circ} / 90^{\circ}$, bottom $45^{\circ} /-45^{\circ}$ ). The spinning dopes contain polyvinyl alcohol (PVOH) with varying double-walled aluminogermanate imogolite nanotubes (DW Ge-INTs) volume fraction ( $\left.\phi_{\mathrm{DW}} \mathrm{Ge- \textrm {INT }}\right)$, in water/dimethyl sulfoxide (DMSO). (a) PVOH solution ( $\phi_{\mathrm{DW}}$ Ge-INT $=0 \%$ ), DW Ge-INT/PVOH suspensions (b) $\phi_{\mathrm{DW} \mathrm{Ge}-\mathrm{INT}}=0.4 \%$, (c) $\phi_{\mathrm{DW} \text { Ge-INT }}=3.8 \%,(\mathrm{~d}) \phi_{\mathrm{DW} \text { Ge-INT }}=8.1 \%$, (e) $\phi_{\mathrm{DW} \mathrm{Ge-INT}}=13.2 \%, 50 \mu \mathrm{m}$ scale bar for all frames. 


\section{Characterization of wet-spun fibers}
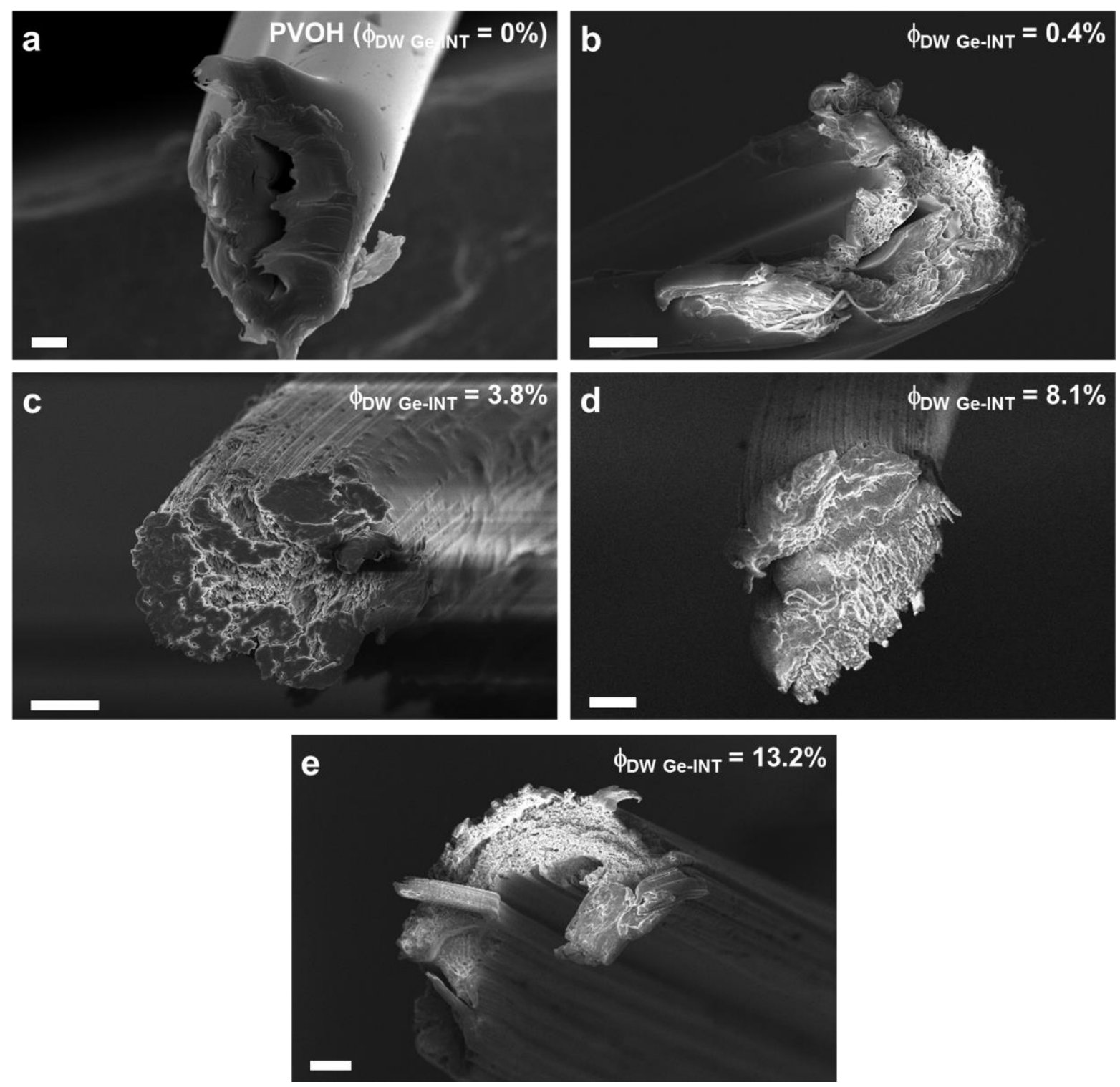

Figure S3 Scanning electron micrographs of cryo-fractured polyvinyl alcohol (PVOH) fiber cross-sections, containing varying fractions of double-walled aluminogermanate imogolite nanotubes (DW Ge-INTs): (a) PVOH fiber ( $\phi_{\text {DW Ge-INT }}=0 \%$ ), DW Ge-INT/PVOH composite fiber (b) $\phi_{\text {DW Ge-INT }}=0.4 \%$, (c) $\phi_{\text {DW Ge-INT }}=3.8 \%$, (d) $\phi_{\text {DW Ge-INT }}=8.1 \%$, (e) $\phi_{\text {DW Ge-INT }}=13.2 \%$, $10 \mu \mathrm{m}$ scale bar for all frames, nominal diameters are provided in Table S2. 


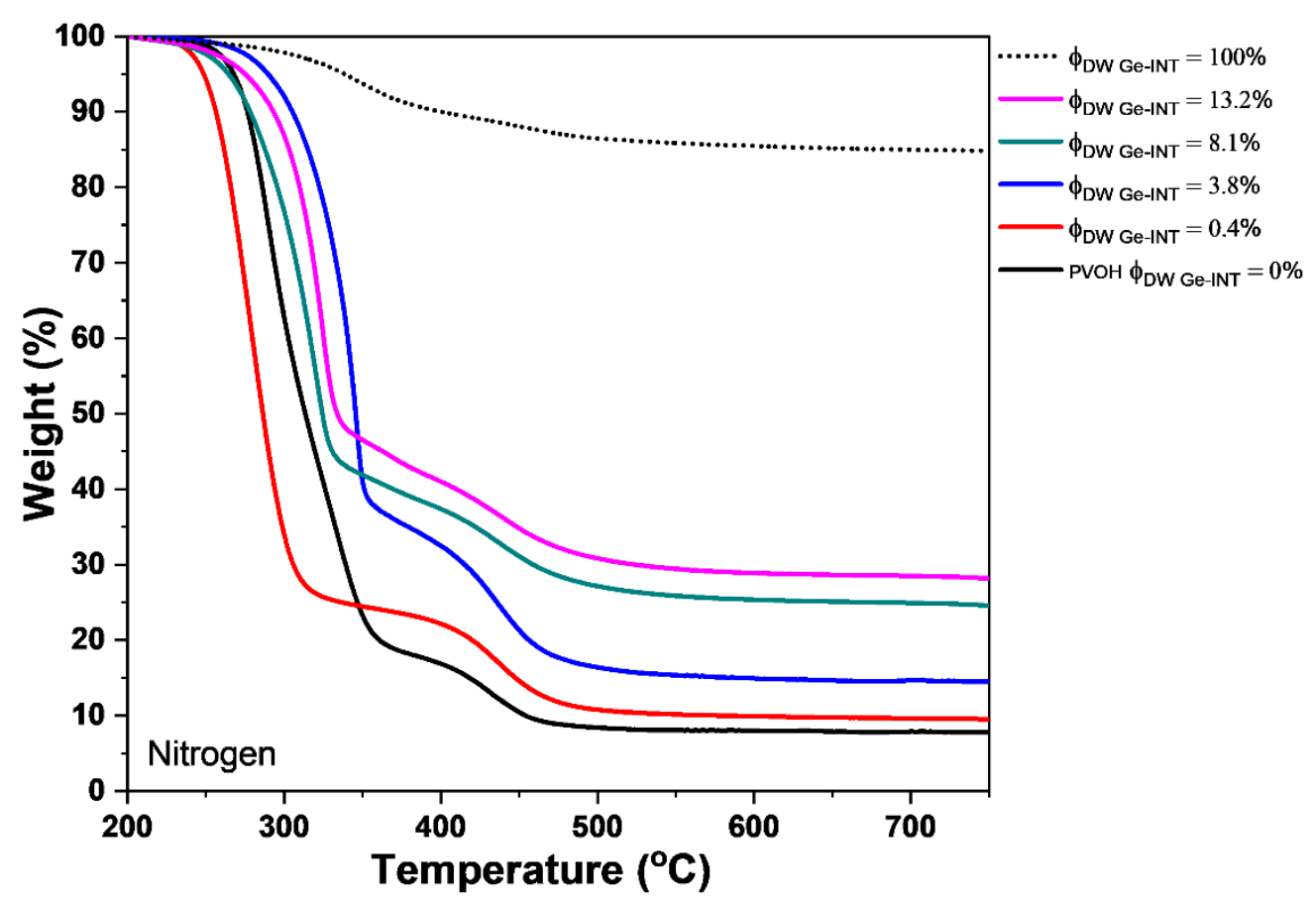

Figure S4 Thermogravimetric analysis of double-walled aluminogermanate imogolite nanotube (DW Ge-INT)/polyvinyl alcohol (PVOH) composite fibers, pure PVOH fiber (control) and the as-synthesized DW Ge-INTs (black). PVOH fiber $\left(\phi_{\text {DW Ge-INT }}=0 \%\right)$, DW Ge INT/PVOH composite fibers: (red) $\phi_{\mathrm{DW}} \mathrm{Ge}-\mathrm{INT}=0.4 \%$, (blue) $\phi_{\mathrm{DW}} \mathrm{Ge}-\mathrm{INT}=3.8 \%$, (turquoise-green) $\phi_{\text {DW Ge-INT }}=8.1 \%,($ pink $) \phi_{\text {DW Ge-INT }}=13.2 \%$, and (black dotted) DW Ge-INTs $\left(\phi_{\text {DW Ge-INT }}=100 \%\right.$, powder $)$, carried out in nitrogen .

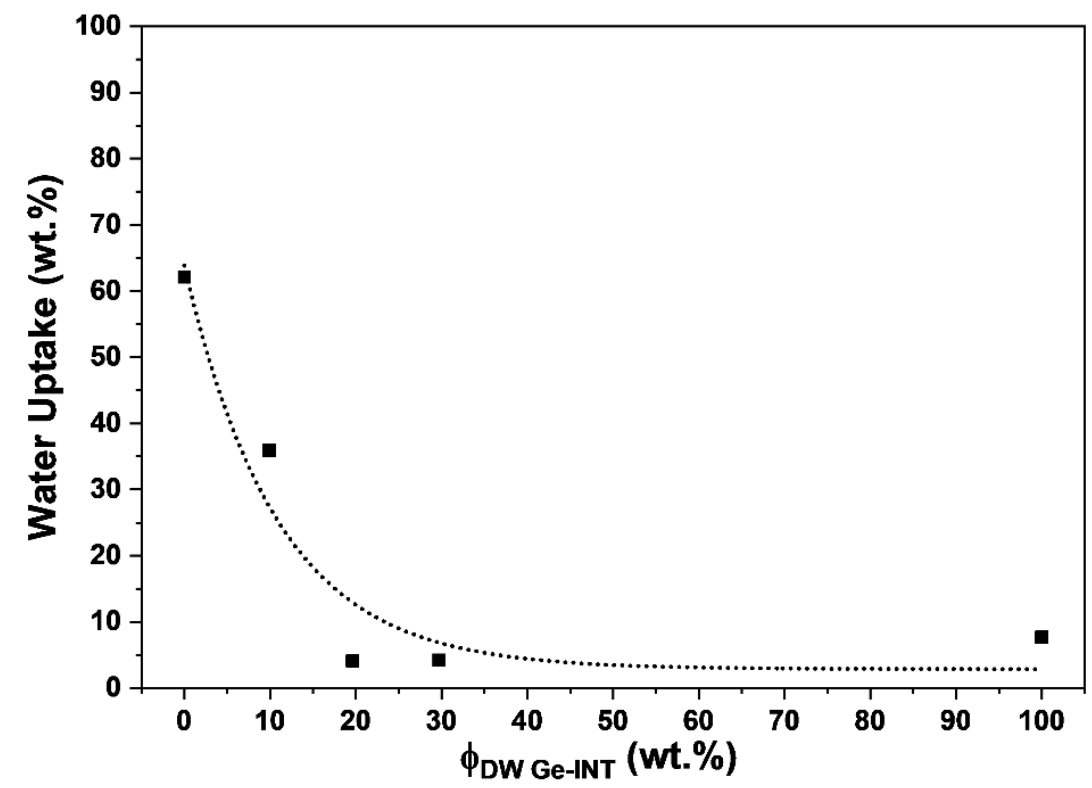

Figure S5 Saturated water content of double-walled aluminogermanate imogolite nanotube (DW Ge-INT)/polyvinyl alcohol (PVOH) composite fibers, pure PVOH fiber (control, 0\%) and assynthesized DW Ge-INTs (control 100\%), as determined by thermogravimetric analysis. The data indicate a lower uptake with increasing INT loading. (Dotted line is a guide for the eye). 

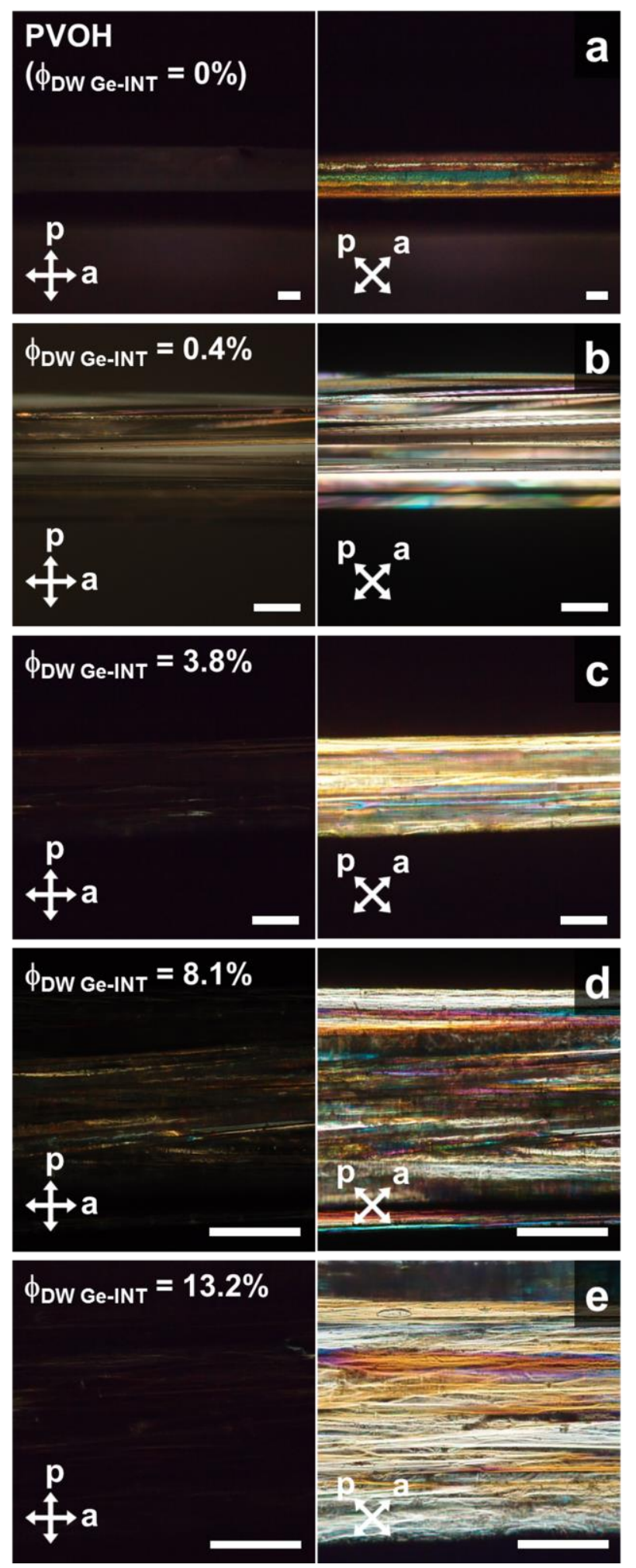

Figure S6 Cross-polarized optical microscopy (left $0^{\circ} / 90^{\circ}$, right $+45^{\circ} /-45^{\circ}$ ) images of doublewalled aluminogermanate imogolite nanotube (DW Ge-INT)/polyvinyl alcohol (PVOH) composite fibers and pure PVOH fiber (control). (a) PVOH fiber $\left(\phi_{\mathrm{DW}}\right.$ Ge-INT $\left.=0 \%\right), \mathrm{DW}$ Ge-INT/PVOH composite fiber (b) $\phi_{\text {DW Ge-INT }}=0.4 \%$, (c) $\phi_{\text {DW Ge-INT }}=3.8 \%,(\mathrm{~d})$ $\phi_{\text {DW Ge-INT }}=8.1 \%,(\mathrm{e}) \phi_{\text {DW Ge-INT }}=13.2 \% .50 \mu \mathrm{m}$ scale bar for all frames. 

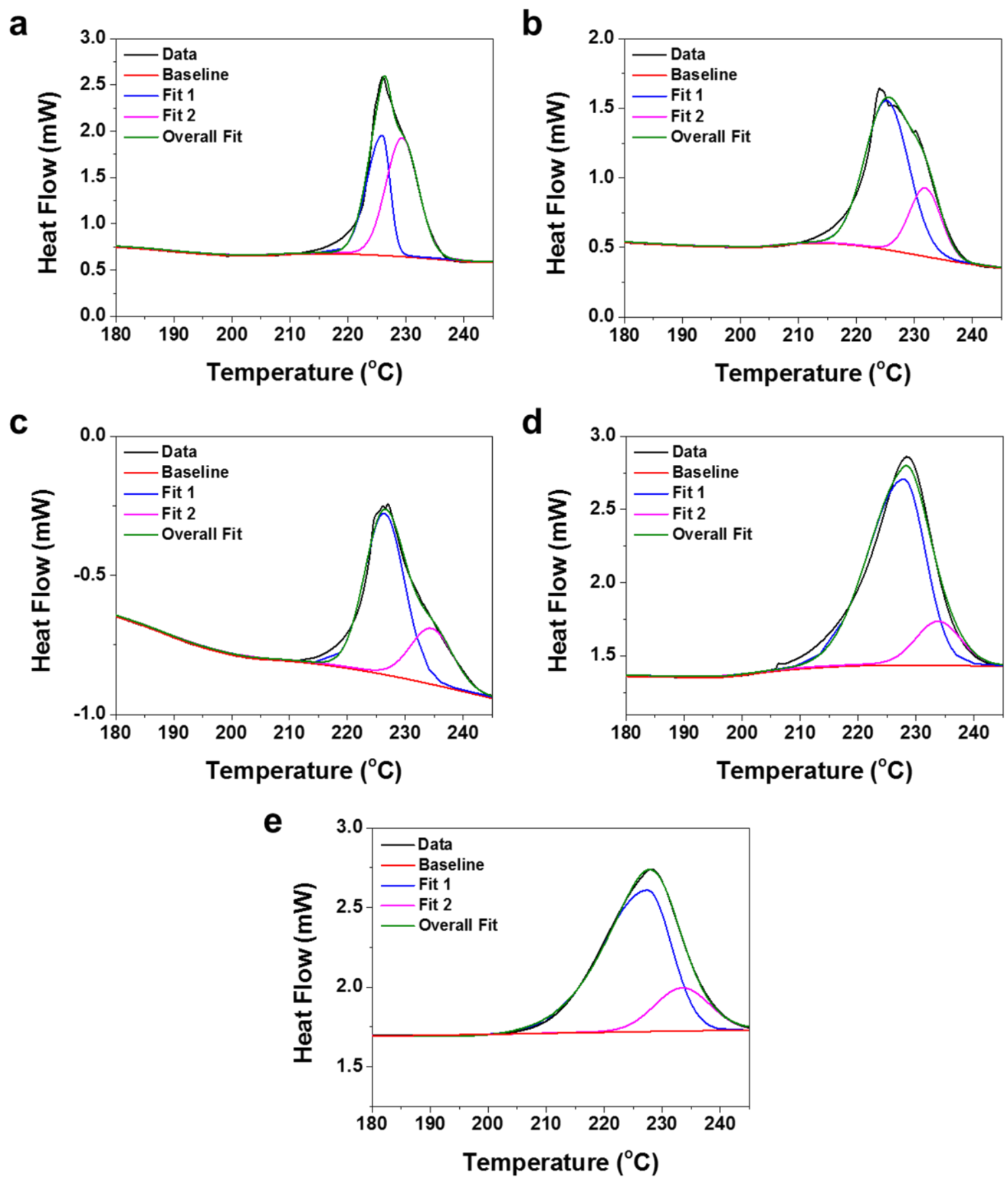

Figure S7 Differential scanning calorimetry (DSC) thermographs of double-walled aluminogermanate imogolite nanotube (DW Ge-INT)/polyvinyl alcohol (PVOH) composite fibers and pure PVOH fiber (control). (a) PVOH fiber ( $\phi_{\mathrm{DW}}$ Ge-INT $=0 \%$ ), DW Ge-INT/PVOH composite fiber (b) $\phi_{\mathrm{DW} \mathrm{Ge}-\mathrm{INT}}=0.4 \%$, (c) $\phi_{\mathrm{DW} \mathrm{Ge}} \mathrm{INT}=3.8 \%$, (d) $\phi_{\mathrm{DW} \text { Ge-INT }}=8.1 \%$, (e) $\phi_{\mathrm{DW} \text { Ge-INT }}=13.2 \%$. Fit 1 (blue), Fit 2 (pink) correspond to the melting and the decomposition peaks of PVOH, respectively. The DSC overall fit (green) includes the contribution of Fit 1 and Fit 2 in relation to the baseline fit (red) and can be compared to the experimental thermograph (black). 
The degree of crystallinity of polyvinyl alcohol (PVOH) content in composite fiber was calculated using the following equation;

$\chi_{c}=\frac{\Delta H_{\mathrm{m}}}{\Delta H_{0}} \times 100$

where $\chi_{c}, \Delta H_{\mathrm{m}}$ and $\Delta H_{0}$ are the degree of crystallinity in weight percentage of the whole fiber, the measured melting endothermic enthalpy, and the theoretical melting enthalpy ${ }^{1}$ of $100 \%$ crystalline PVOH (156 J g $\mathrm{g}^{-1}$ ), respectively. As the addition of double-walled aluminogermanate imogolite nanotubes did not alter the melting temperature, it was considered not to provide a contribution to the measured melting endothermic enthalpy of the crystalline PVOH.

Table S1 Composition and thermal data for double-walled aluminogermanate imogolite nanotube (DW Ge-INT)/polyvinyl alcohol (PVOH) composite fibers and pure PVOH fiber (control). Degree of crystallinity $\left(\chi_{\mathrm{c}}\right)$, in weight fraction, determined through differential scanning calorimetry as described above. Linear density of the fibers, by direct measurement, as described elsewhere in the methods.

\begin{tabular}{|c|c|c|c|c|c|c|}
\hline $\begin{array}{c}\text { DW } \\
\text { Ge-INT/PVOH } \\
\text { fiber composition } \\
{[\text { vol.\%] }}\end{array}$ & $\begin{array}{c}\text { Melting } \\
\text { temperature }\end{array}$ & {$\left[\mathbf{J} \mathbf{~ g}^{-1}\right]$} & $\begin{array}{c}\text { DW } \\
\text { Ge-INT } \\
\text { content } \\
\text { [wt.\%] }\end{array}$ & $\begin{array}{c}\text { PVOH } \\
\text { degree of } \\
\text { crystallinity } \\
\left(\chi_{c}\right) \\
{[w t . \%]}\end{array}$ & $\begin{array}{c}\text { PVOH } \\
\text { amorphous } \\
\text { content } \\
\text { [wt.\%] }\end{array}$ & $\begin{array}{c}\text { Linear } \\
\text { density } \\
\left(\delta_{L}\right) \\
{[\text { tex }]}\end{array}$ \\
\hline$\phi$ DW Ge-INT $=0 \%$ & 225.9 & 33.65 & 0.00 & 21.57 & 78.43 & 1.9 \\
\hline$\phi_{\mathrm{DW} \text { Ge-INT }}=0.4 \%$ & 225.2 & 35.19 & 1.00 & 22.56 & 76.44 & 1.9 \\
\hline$\phi_{\mathrm{DW} \text { Ge-INT }}=3.8 \%$ & 226.3 & 46.29 & 9.91 & 29.67 & 60.42 & 1.2 \\
\hline$\phi_{\mathrm{DW} \text { Ge-INT }}=8.1 \%$ & 227.6 & 50.56 & 19.64 & 32.41 & 47.95 & 2.1 \\
\hline$\phi_{\mathrm{DW} \text { Ge-INT }}=13.2 \%$ & 227.4 & 42.47 & 29.68 & 27.23 & 43.10 & 4.5 \\
\hline
\end{tabular}


Table S2 Composition, in volume fractions, of double-walled aluminogermanate imogolite nanotube (DW Ge-INT)/polyvinyl alcohol (PVOH) composite fibers and pure PVOH fiber (control) determined from the weight fractions in Table S1, and the material densities:

$1.269 \mathrm{~g} \mathrm{~cm}^{-3}$ and $1.345 \mathrm{~g} \mathrm{~cm}^{-3}$ for amorphous $\mathrm{PVOH}$ and crystalline $\mathrm{PVOH},{ }^{2}$ respectively; the DW Ge-INTs density, $3.6 \mathrm{~g} \mathrm{~cm}^{-3}$ was calculated as the ratio between the mass of a nanotube over its period divided by the corresponding volume of the two walls of the nanotubes. Atomic positions were determined via wide angle X-ray scattering analysis, ${ }^{3}$ and adjusted to account for $\mathrm{H}$ atoms ${ }^{4}$ to which $\mathrm{X}$-rays are rather insensitive. The composite fiber bulk density was calculated from the rule-of-mixtures (RoM) addition of the constituent densities. The linear fiber density (in tex, Table S1), was used to calculate the mechanical properties in N/tex directly (Table S5), which were then converted to mechanical properties in GPa, using the estimated composite fiber bulk density. For reference, the measured linear density in tex, and estimated bulk density, can be converted to an implied calculated mean fiber radius, shown in the Table below. Independent measurements of the nominal (circular) composite fiber radii determined by scanning electron microscopy are also tabulated and show reasonable agreement with the density derived values; however, the linear density approach is considered to be more accurate at it averages over the whole fiber sample, and underestimates rather than overestimates the mechanical properties when diameter varies.

\begin{tabular}{|c|c|c|c|c|c|c|}
\hline $\begin{array}{c}\text { DW } \\
\text { Ge-INT/PVOH } \\
\text { fiber composition } \\
{[\text { vol.\%] }}\end{array}$ & $\begin{array}{c}\text { DW } \\
\text { Ge-INT } \\
\text { content } \\
{[\text { vol. } \%]}\end{array}$ & $\begin{array}{c}\text { PVOH } \\
\text { degree of } \\
\text { crystallinity } \\
\text { [vol.\%] }\end{array}$ & $\begin{array}{c}\text { PVOH } \\
\text { amorphous } \\
\text { content } \\
\text { [vol. \%] }\end{array}$ & $\begin{array}{c}\text { Composite } \\
\text { fiber bulk } \\
\text { density }(\delta \mathrm{B}) \\
{\left[\mathrm{g} \mathrm{cm}^{-3}\right]}\end{array}$ & $\begin{array}{c}\text { Calculated } \\
\text { fiber radius } \\
{[\mu \mathrm{m}]}\end{array}$ & $\begin{array}{c}\text { Nominal } \\
\text { fiber radius } \\
\text { from } \mathrm{SEM} \\
{[\mu \mathrm{m}]}\end{array}$ \\
\hline$\phi$ DW Ge-INT $=0 \%$ & 0.0 & 20.6 & 79.4 & 1.28 & 22 & 29 \\
\hline$\phi_{\mathrm{DW}} \mathrm{Ge- \textrm {INT }}=0.4 \%$ & 0.4 & 21.7 & 77.9 & 1.29 & 22 & 15 \\
\hline$\phi_{\mathrm{DW} \text { Ge-INT }}=3.8 \%$ & 3.8 & 30.5 & 65.7 & 1.38 & 17 & 17 \\
\hline$\phi \mathrm{DW}$ Ge-INT $=8.1 \%$ & 8.1 & 35.8 & 56.1 & 1.49 & 21 & 23 \\
\hline$\phi_{\mathrm{DW} \text { Ge-INT }}=13.2 \%$ & 13.2 & 32.4 & 54.4 & 1.60 & 30 & 25 \\
\hline
\end{tabular}

The volume fraction of DW Ge-INTs in the composite fibers is given by;

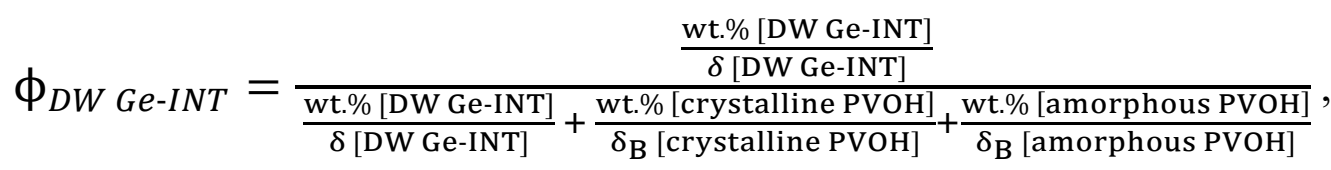

where wt. $\%$ is weight percentage, $\delta$ is density, and $\delta_{\mathrm{B}}$ is bulk density. 


\section{Orientational order parameter determination for double-walled aluminogermanate imogolite nanotube and polyvinyl alcohol fibers}

As detailed in the manuscript, for the wide-angle X-ray scattering experiments, the angular scattered intensity $Q$ values at 0.6 and $1.4 \AA^{-1}$ correspond to scattering features located in the equatorial plane perpendicular to the double-walled aluminogermanate imogolite nanotubes (DW Ge-INTs) and polyvinyl alcohol (PVOH) long axes, respectively. Azimuthal scans, $I_{Q}(\tau)$, in Figure S8 of the composite fibers, are fitted by Lorentzian functions, characterized by their half-width-at-half-maximum (HWHM, $w_{d}$ ), plus two Gaussian functions at $+/-28^{\circ}$ from the Lorentzian for DW Ge-INT/PVOH $\phi$ DW Ge-INT $=13.2 \%$ composite fiber. Note that due to the overlap of the diffuse peak of amorphous PVOH and $10 \overline{1}$ and 101 peaks of crystalline $\mathrm{PVOH}$, amorphous and crystalline contributions cannot be clearly assigned. Angular intensity distribution measured in reciprocal space can be directly calculated from the orientation distribution function $p(\theta)$ in direct space, with $\theta$ being the angle between the wet-spun fiber axis and the nanotube (or PVOH) long axis ${ }^{5}$;

$I_{Q}(\tau) \propto \int_{0}^{90} p\left[\cos ^{-1}\left\{\cos (\xi) \sin \left(\cos ^{-1}\left[\cos \left(\theta_{B}\right) \cos (\tau)\right]\right)\right\}\right] d \xi$

where $\tau, \theta_{B}$ and $\xi$ are the azimuthal angle, Bragg angle and a variable, respectively. Lorentzian curves in Figure S8 are well reproduced for Lorentzian functions to the power 1.5 in direct space $\left(L_{w_{d}}^{3 / 2}\right)$, so that;

$p(\theta)=\frac{L_{w_{d}}^{3 / 2}(\theta)}{4 \pi \int_{0}^{90} L_{w_{d}}^{3 / 2}(\theta) \sin (\theta) d \theta}$,

with,

$L_{w_{d}}^{3 / 2}(\theta)=\frac{1}{\left[1+\left(\frac{0.7664 \theta}{w_{d}}\right)^{2}\right]^{1.5}}\left(0 \leq \theta \leq 90^{\circ}\right)$

Finally, one calculates the orientational order parameter;

$S=<\frac{3 \cos ^{2}(\theta)-1}{2}>=\frac{12 \pi \int_{0}^{90} p(\theta) \cos ^{2}(\theta) \sin (\theta) d \theta-1}{2}$

Table S3 provides the values of the HWHM of the Lorentzian orientational distribution of DW Ge-INTs and PVOH, as well as the calculated values of $S$. In the case of the $\phi_{\text {DW Ge-INT }}=13.2 \%$ fiber, for $Q=1.4 \AA^{-1}$, the distribution of intensity in reciprocal space is notably different from the one at $Q=0.6 \AA^{-1}$. It is found to be fitted by the following sum of a Lorentzian function and of two Gaussian functions:

$I_{Q}(\tau) \propto \frac{1}{1+\left(\frac{\tau-90}{8}\right)^{2}}+0.13 e^{-\ln 2((\tau-62 .) / 12)^{2}}+0.13 e^{-\ln 2((\tau-108 .) / 12)^{2}}$,

with the corresponding orientational distribution function described as

$p(\theta) \propto \frac{1}{\left[1+\left(\frac{0.7664 \theta}{6}\right)^{2}\right]^{1.5}}+0.04 e^{-\ln 2((\theta-34 .) / 9)^{2}}\left(0 \leq \theta \leq 90^{\circ}\right)$. 


\section{PVOH}

$\left(\phi_{\text {DW Ge-INT }}=0 \%\right)$

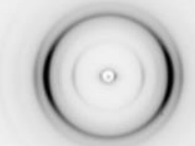

$\phi_{\text {DW Ge-INT }}=0.4 \%$
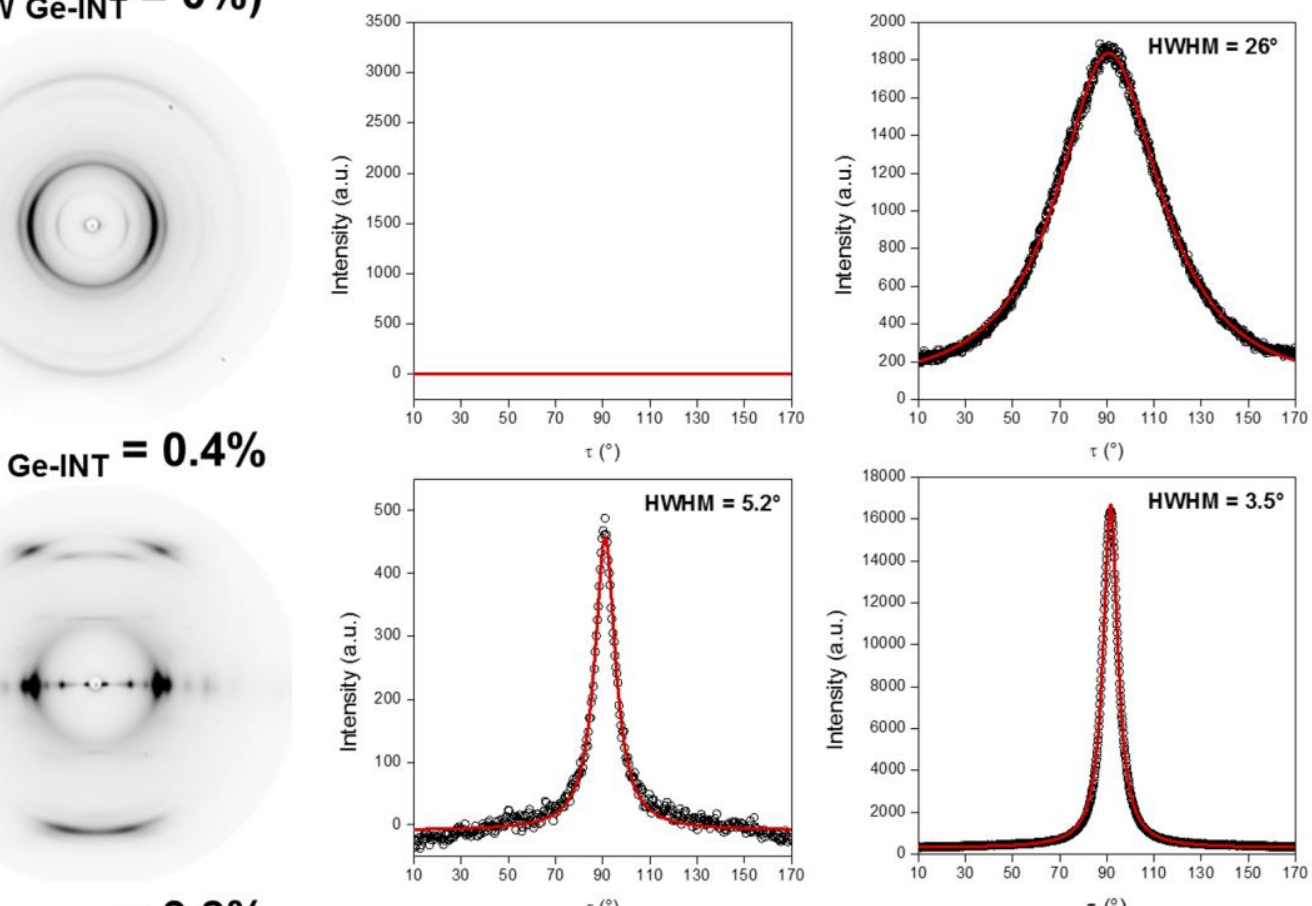

$\phi_{\text {DW Ge-INT }}=3.8 \%$
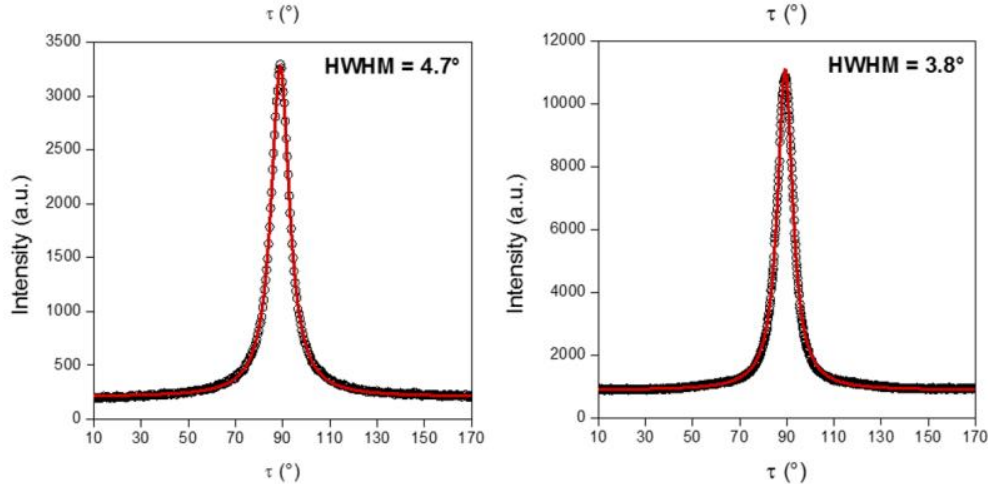

$\phi_{\text {DW Ge-INT }}=8.1 \%$
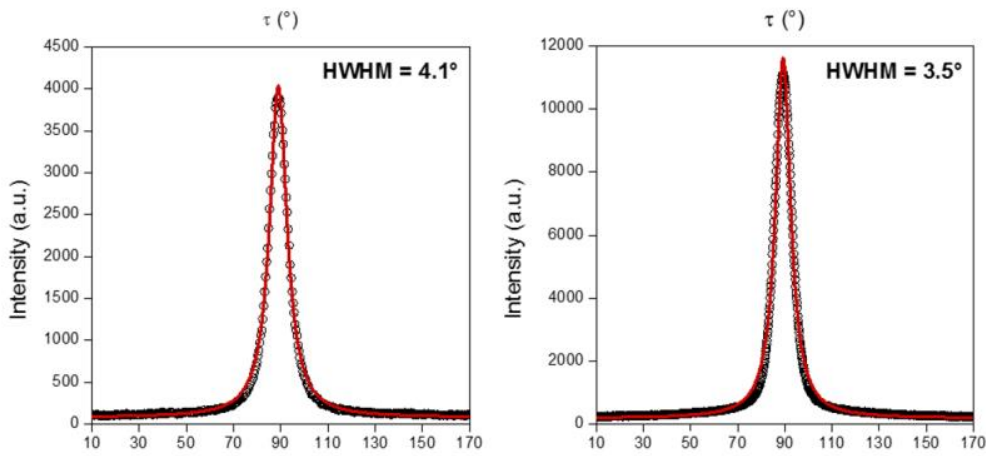

$\phi_{\text {DW Ge-INT }}=13.2 \%$
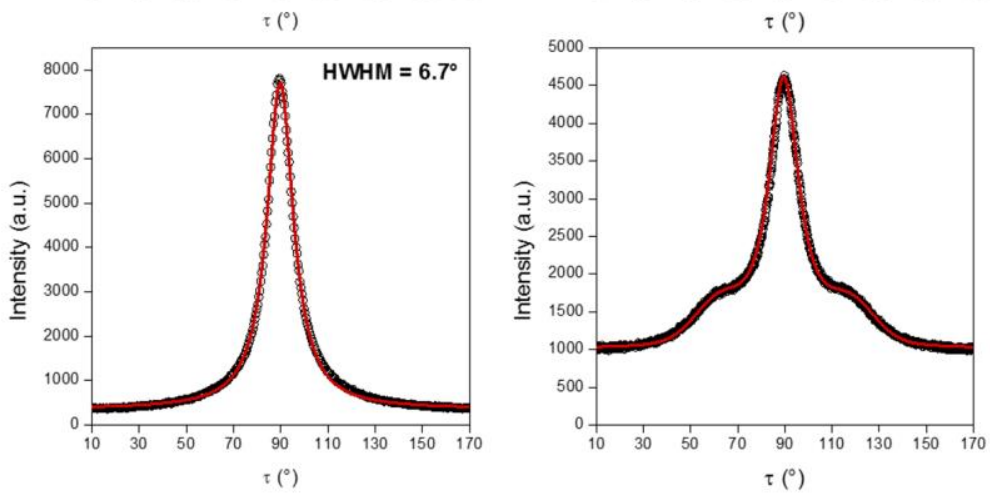
Figure S8 Characterization of the orientation parameters of the constituents in double-walled aluminogermanate imogolite nanotube (DW Ge-INT)/polyvinyl alcohol (PVOH) composite fibers and pure PVOH fiber (control, $\phi_{\mathrm{DW}} \mathrm{Ge-INT}=0 \%$ ). Left column: Two dimensional wide-angle X-ray scattering pattern, center column: angular scattered intensity at $Q=0.6 \AA^{-1}$ corresponding to a maximum of the form factor of DW Ge-INT and angular scattered intensity at $Q=1.4 \AA^{-1}$, corresponding to the diffraction from crystalline and amorphous $\mathrm{PVOH}$.

Experimental values (open black circles) and Lorentzian fitting (red line), with corresponding HWHM, provided. In the case of the DW Ge-INT/PVOH composite fiber $\phi_{\text {DW Ge-INT }}=13.2 \%$, the fit was performed with a Lorentzian function $\left(\mathrm{HWHM}=8^{\circ}\right)$ and two Gaussian functions $\left(\mathrm{HWHM}=12^{\circ}\right)$ at $62^{\circ}$ and $118^{\circ}$, following Equation S8.

Table S3 Determination of the orientation order parameters, $S$, for double-walled aluminogermanate imogolite nanotube (DW Ge-INT)/polyvinyl alcohol (PVOH) composite fibers and pure $\mathrm{PVOH}$ fiber $\left(\phi_{\mathrm{DW}} \mathrm{Ge- \textrm {INT }}=0 \%\right)$ from angular scattered intensity plots shown in Figure S8. Half-width-at-half-maximum (HWHM, $w_{d}$ ) are reported for fitting Lorentzian functions to the power 1.5, which describe the orientation distribution functions in direct space, and allow the fitting of the azimuthal curves at $Q=0.6$ and $1.4 \AA^{-1}$, which correspond to DW Ge-INTs and PVOH scattering, respectively. In the specific case of DW Ge-INT/PVOH $\phi_{\text {Ge-INT }}=13.2 \%$ composite fibers, the orientation distribution function is found to be given by the sum of two functions, a Lorentzian function to the power $1.5\left(\mathrm{HWHM}=6^{\circ}\right)$ and a Gaussian function centered at $\theta \approx 34^{\circ}$, with HWHM $=9^{\circ}$, Equation S8. Moreover, in this case only, one cannot rule out the possibility that a fraction of the PVOH molecules is fully disoriented (see reference Pichot et al. ${ }^{5}$ for more details on the related two-phases), so that the calculated orientation parameter value reported in the table is only an upper limit. Accuracy on the values of the orientation order parameter $S_{\mathrm{INT}}\left(S_{\mathrm{PVOH}}\right)$ is mainly limited by uncertainties in the values of HWHM, determined by performing azimuthal scans at other $Q$-values where INT and PVOH contributions are dominant. A value of unity would signify full alignment of the species with respect to the fiber axis.

\begin{tabular}{ccccc}
\hline $\begin{array}{c}\text { DW Ge-INT/PVOH } \\
\text { fiber composition } \\
\text { [vol. } \% \text { ] }\end{array}$ & $\begin{array}{c}\boldsymbol{w}_{\boldsymbol{d}}\left({ }^{\circ}\right) \\
\text { DW } \\
\text { Ge-INT }\end{array}$ & $\begin{array}{c}\boldsymbol{w}_{\boldsymbol{d}}\left({ }^{\circ}\right) \\
\text { PVOH }\end{array}$ & $\boldsymbol{S}_{\text {DW Ge-INT }}$ & $\boldsymbol{S}_{\text {PVOH }}$ \\
\hline$\phi_{\mathrm{DW} \text { Ge-INT }}=0 \%$ & NA & 20.0 & NA & $0.50 \pm 0.05$ \\
$\phi_{\text {DW Ge-INT }}=0.4 \%$ & 4.0 & 2.6 & $0.86 \pm 0.05$ & $0.91 \pm 0.05$ \\
$\phi_{\text {DW Ge-INT }}=3.8 \%$ & 3.6 & 2.9 & $0.87 \pm 0.05$ & $0.90 \pm 0.05$ \\
$\phi_{\text {DW Ge-INT }}=8.1 \%$ & 3.1 & 2.6 & $0.89 \pm 0.05$ & $0.91 \pm 0.05$ \\
$\phi_{\text {DW Ge-INT }}=13.2 \%$ & 5.1 & - & $0.83 \pm 0.05$ & $\leq 0.7$ \\
\hline
\end{tabular}


The crystallite size in the DW Ge-INTs/PVOH composite fiber ( $\phi_{\mathrm{DW}} \mathrm{Ge}-\mathrm{INT}=3.8 \%$ ) reported in Figure 1 was compared that obtained from a diffraction experiment on a conventional, commercial PVOH fiber reference (Figure S9).

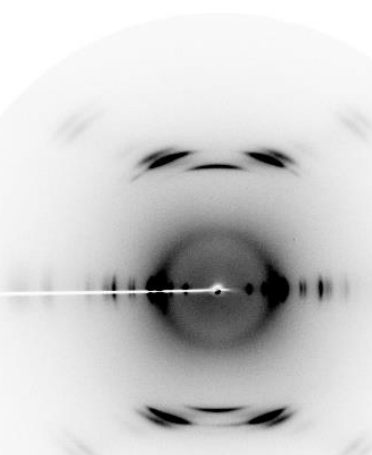

Figure S9 Two dimensional wide angle X-ray scattering pattern of a commercial PVOH fiber Kuralon 1239, manufactured by Kuraray Co. Ltd.

Table S4 Full-width-at-half-maximum (FWHM) and the average crystallite size (L) estimated using the Scherrer equation for crystal axes 001 or 200, for a commercial PVOH fiber (Kuralon 1239 ) and a wet-spun DW Ge INTs/PVOH composite fiber ( $\phi W$ Ge-INT $=3.8 \%$ ).

\begin{tabular}{ccccc}
\hline & $\begin{array}{c}\text { FWHM_001 } \\
\text { Q001 }=\mathbf{1 . 1 4 5} \\
{\left[\AA^{-1}\right]}\end{array}$ & $\begin{array}{c}\text { FWHM_200 } \\
\mathbf{Q}_{200}=\mathbf{1 . 6} \\
{\left[\AA^{-1}\right]}\end{array}$ & $\begin{array}{c}\text { Lo01 } \\
{[\mathbf{n m}]}\end{array}$ & $\begin{array}{c}\text { L200 } \\
{[\mathbf{n m}]}\end{array}$ \\
\hline Kuralon 1239 & 0.057 & 0.065 & 22 & 20 \\
$\phi_{\text {DW Ge-INT }}=3.8 \%$ & 0.038 & 0.05 & 33 & 26 \\
\hline
\end{tabular}




\section{Mechanical modelling equations, tabulated data and healed composite fiber stress-strain curves}

The tensile stiffness of double-walled aluminogermanate imogolite nanotube (DW Ge-INT)/polyvinyl alcohol (PVOH) composite fibers can be predicted using the well-known rule-of-mixtures (RoM). However, when the reinforcing components are anisotropic, additional efficiency factors are required to take into account orientation and stress transfer variations. Krenchel's modified RoM equation is given below:

$E=\eta_{0} \eta_{l_{\mathrm{DW} \mathrm{Ge-INT}}} \phi_{\mathrm{DW} \mathrm{Ge}-\mathrm{INT}} E_{\mathrm{DW} \mathrm{Ge-INT}}+\phi_{\mathrm{m}} E_{\mathrm{m}}$,

where $\eta_{0}, \eta_{l_{\mathrm{DW} \mathrm{Ge-INT}}}$ are efficiency factors relating to DW Ge-INT orientation and length, $\phi_{\mathrm{DW}}$ Ge-INT, $\phi_{\mathrm{m}}$ are volume fraction of DW Ge-INT and matrix, and $E, E_{\mathrm{DW} \text { Ge-INT, }} E_{\mathrm{m}}$ are the moduli (in GPa) of composite fiber, DW Ge-INT and matrix, respectively. The DW Ge-INT

orientation efficiency factor $\left(\eta_{o}\right)^{6}$ and the DW Ge-INT efficiency length factor $\left(\eta_{l_{\mathrm{DW} \mathrm{Ge}-\mathrm{INT}}}\right),{ }^{7}$ are given by;

$\eta_{0}=<\cos ^{4} \theta>$

$\eta_{l_{\mathrm{DW} \mathrm{Ge}-\mathrm{INT}}}=1-\frac{\tanh \beta}{\beta}+$

where,

$\beta=2 \frac{l_{\mathrm{DW} \mathrm{Ge}-\mathrm{INT}}}{D} \sqrt{\frac{G_{\mathrm{m}}}{E_{\mathrm{DW} \mathrm{Ge}-\mathrm{INT}} \ln \left(\frac{K_{R}}{\phi_{\mathrm{DW} \text { Ge-INT }}}\right)}}+$

'R01(

where $\theta$ is taken from the azimuthal curves at $Q=0.6$, and $l_{\mathrm{DW} \text { Ge-INT }}$ and $D$ are DW Ge-INT length (c.a. $85 \mathrm{~nm}$ ) and diameter (c.a. $4.3 \mathrm{~nm}) .{ }^{8} G_{\mathrm{m}}$ is the shear modulus of the matrix in $\mathrm{GPa}$ (ca. $1.7 \mathrm{GPa}$ for $\mathrm{PVOH}),{ }^{9}$ and $K_{R}$ is a constant equal to 1 for cylinders in shear lag models. ${ }^{10}$

However, when Equation S9 was used, fitting a single semi-crystalline PVOH modulus $(10-30 \mathrm{GPa})^{11}$, there was a poor fit to the data. Additional consideration of the varying crystalline/amorphous proportions was required to gain a good fit. The crystalline to amorphous content in composite fibers was determined via differential scanning calorimetry, Figure S7.

Krenchel's model was then adapted as follows:

$E=\eta_{o} \eta_{l_{\mathrm{DW} \mathrm{Ge}-\mathrm{INT}}} \phi_{\mathrm{DW} \mathrm{Ge-INT}} E_{\mathrm{DW} \mathrm{Ge-INT}}+\phi_{\mathrm{m} . \mathrm{a}} E_{\mathrm{m} . \mathrm{a}}+\phi_{\mathrm{m} . \mathrm{c}} E_{\mathrm{m} . \mathrm{c}}$,

where $\phi_{\mathrm{m} . \mathrm{a}}, \phi_{\mathrm{m} . \mathrm{c}}$ are volume fractions of amorphous and crystalline $\mathrm{PVOH}$ matrix, and $E_{\mathrm{m} . \mathrm{a}}, E_{\mathrm{m} . \mathrm{c}}$ are the moduli of amorphous and crystalline PVOH, respectively.

Assuming,

$V_{\mathrm{f}}+V_{\mathrm{m} . \mathrm{a}}+V_{\mathrm{m} . \mathrm{c}}=1$

where $V_{\mathrm{f}}, V_{\mathrm{m} . \mathrm{a}}$ and $V_{\mathrm{m} . \mathrm{c}}$ are volume fractions of imogolite reinforcement, amorphous matrix and crystalline matrix, respectively. 
The moduli substituted into Equation S13 were $328 \mathrm{GPa},{ }^{12} 3.75 \mathrm{GPa},{ }^{13} 37 \mathrm{GPa}^{14}$ for DW Ge-INT ((12,0)@(21,0)), amorphous and crystalline PVOH, respectively. The volume fractions of PVOH and DW Ge-INT were determined from weight fractions added to the spinning dope and the material densities, $3.6 \mathrm{~g} \mathrm{~cm}^{-3}, 1.269 \mathrm{~g} \mathrm{~cm}^{-3}$ and $1.345 \mathrm{~g} \mathrm{~cm}^{-3}$ for DW Ge-INTs (details on page 9, Supporting Information), amorphous $\mathrm{PVOH}$ and crystalline $\mathrm{PVOH},{ }^{2}$ respectively.

Table S5 Tabulated tensile properties of double-walled aluminogermanate imogolite nanotube (DW Ge-INT)/polyvinyl alcohol (PVOH) composite fibers and pure PVOH fiber (control, $\phi_{\text {DW Ge-INT }}=0 \%$ ), with Krenchel's micromechanical reinforcing efficiency factors, and the resulting tensile modulus determined from the modified rule-of-mixtures (RoM).

\begin{tabular}{|c|c|c|c|c|c|c|}
\hline $\begin{array}{c}\text { DW } \\
\text { Ge-INT/PVOH } \\
\text { composite fibers } \\
\text { [vol.\%] }\end{array}$ & $\begin{array}{l}\text { Tensile } \\
\text { modulus } \\
\quad(E) \\
{\left[\mathrm{N} \text { tex }^{-1}\right]}\end{array}$ & $\begin{array}{l}\text { Tensile } \\
\text { strength } \\
\quad(\sigma) \\
{\left[\mathrm{N} \mathrm{tex}^{-1}\right]}\end{array}$ & $\begin{array}{c}\text { Tensile } \\
\text { modulus } \\
\quad(E) \\
{[G P a]}\end{array}$ & $\begin{array}{c}\text { Tensile } \\
\text { strength } \\
\quad(\sigma) \\
{[\mathrm{MPa}]}\end{array}$ & 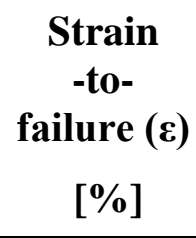 & $\begin{array}{c}\text { RoM } \\
\text { tensile } \\
\text { modulus } \\
\text { [GPa] }\end{array}$ \\
\hline$\phi_{\text {DW Ge-INT }}=0 \%$ & $7.49 \pm 1.49$ & $0.45 \pm 0.08$ & $9.87 \pm 2.61$ & $603 \pm 71$ & $9.0 \pm 1.5$ & 10.6 \\
\hline$\phi$ DW Ge-INT $=0.4 \%$ & $10.10 \pm 0.83$ & $0.43 \pm 0.05$ & $13.27 \pm 0.83$ & $559 \pm 64$ & $6.9 \pm 0.5$ & 11.2 \\
\hline$\phi_{\mathrm{DW} \text { Ge-INT }}=3.8 \%$ & $12.32 \pm 1.24$ & $0.47 \pm 0.04$ & $18.79 \pm 1.24$ & $712 \pm 68$ & $5.9 \pm 0.4$ & 18.1 \\
\hline$\phi_{\mathrm{DW} \text { Ge-INT }}=8.1 \%$ & $14.09 \pm 1.81$ & $0.45 \pm 0.03$ & $24.11 \pm 1.81$ & $794 \pm 56$ & $5.4 \pm 0.5$ & 26.1 \\
\hline$\phi_{\text {DW Ge-INT }}=13.2 \%$ & $9.31 \pm 2.65$ & $0.25 \pm 0.05$ & $18.58 \pm 2.65$ & $506 \pm 99$ & $5.8 \pm 1.4$ & 31.7 \\
\hline
\end{tabular}

Table S6 Tabulated tensile properties of healed composite fibers. The polyvinyl alcohol control could not be healed using the same procedure.

\begin{tabular}{|c|c|c|c|c|c|}
\hline $\begin{array}{c}\text { DW } \\
\text { Ge-INT/PVOH } \\
\text { composite fibers } \\
\text { [vol.\%] }\end{array}$ & $\begin{array}{c}\text { Tensile } \\
\text { modulus } \\
(E) \\
{[\text { GPa] }}\end{array}$ & $\begin{array}{c}\text { Tensile } \\
\text { strength } \\
(\sigma) \\
{[\mathrm{MPa}]}\end{array}$ & $\begin{array}{c}\text { Strain } \\
\text {-to- } \\
\text { failure }(\varepsilon) \\
{[\%]}\end{array}$ & $\begin{array}{c}\begin{array}{c}\text { Stiffness } \\
\text { healing } \\
\text { efficiency }\end{array} \\
\left(\alpha_{E}\right)[\%]\end{array}$ & $\begin{array}{r}\begin{array}{c}\text { Strength } \\
\text { healing } \\
\text { efficiency }\end{array} \\
\left(\alpha_{\sigma}\right)[\%] \\
\end{array}$ \\
\hline$\phi D W$ Ge-INT $=0 \%$ & NA & NA & NA & NA & NA \\
\hline$\phi$ DW Ge-INT $=0.4 \%$ & $1.19 \pm 0.52$ & $16.10 \pm 5.50$ & $3.19 \pm 0.24$ & 8.94 & 2.88 \\
\hline$\phi_{\mathrm{DW} \text { Ge-INT }}=3.8 \%$ & $4.84 \pm 1.47$ & $61.72 \pm 15.30$ & $2.53 \pm 0.21$ & 25.75 & 8.67 \\
\hline$\phi$ DW Ge-INT $=8.1 \%$ & $6.76 \pm 0.95$ & $93.10 \pm 9.85$ & $2.10 \pm 0.15$ & 28.05 & 11.72 \\
\hline$\phi_{\mathrm{DW} \text { Ge-INT }}=13.2 \%$ & $8.10 \pm 1.78$ & $97.65 \pm 11.08$ & $1.48 \pm 0.22$ & 43.57 & 19.30 \\
\hline
\end{tabular}




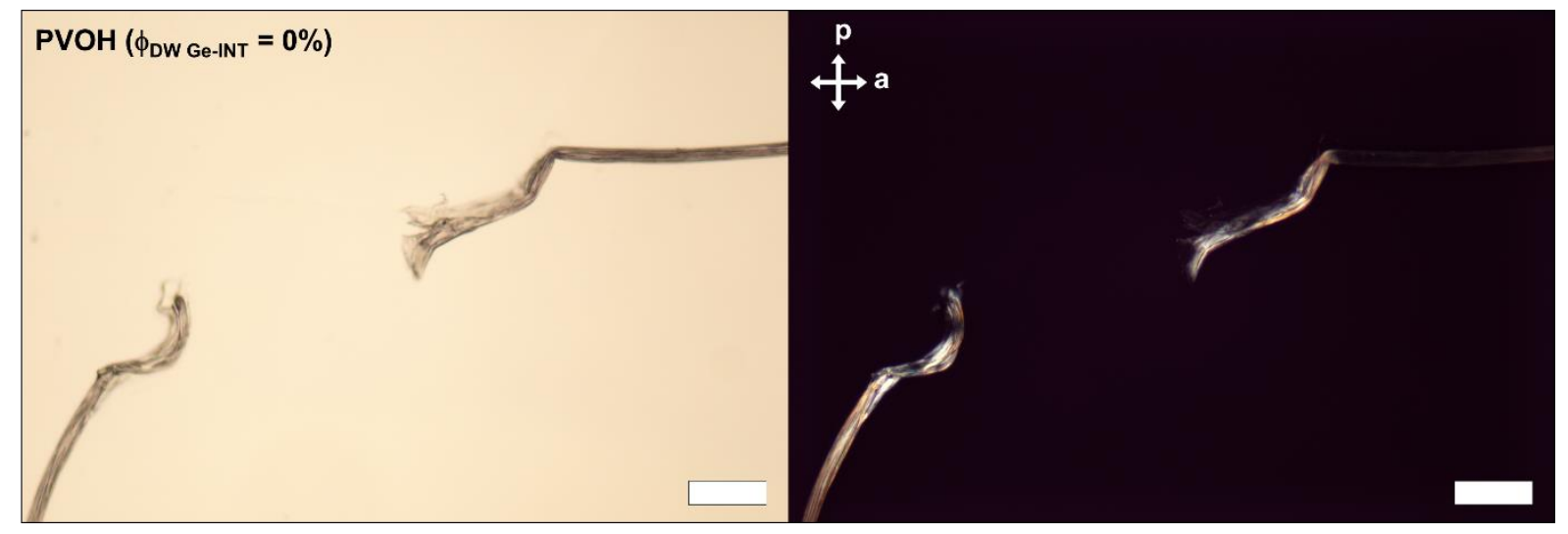

Figure S10 Transmission optical micrographs under normal illumination (left) and with crossed polarizers (right), showing the response of PVOH fiber $\left(\phi_{\mathrm{DW} \text { Ge INT }}=0 \%\right)$ under 'healing conditions', including contraction and distortion, $100 \mu \mathrm{m}$ scale bar for both micrographs.
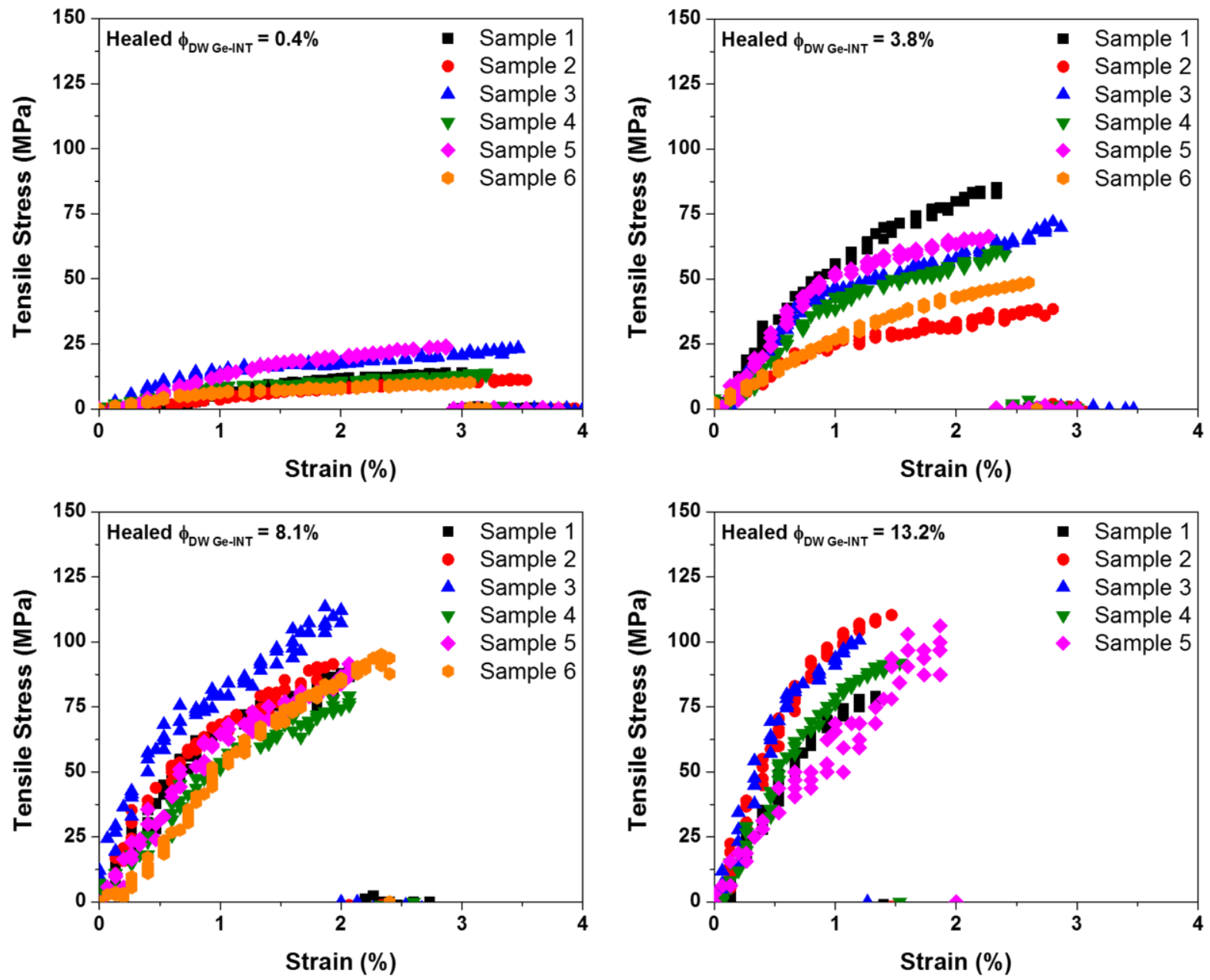

Figure S11 Tensile stress-strain curves for healed composite fibers double-walled aluminogermanate imogolite nanotube (DW Ge-INT)/polyvinyl alcohol (PVOH) composite fibers. 
Table S7 Tensile mechanical properties of healed materials found in literature. Tensile modulus $(E)$, ultimate tensile stress (UTS), strain-to-failure $(\varepsilon)$, healing time $\left(\alpha_{\text {time }}\right)$, healing temperature $\left(\alpha_{\text {Temp. }}\right)$, stiffness healing efficiency $\left(\alpha_{E}\right)$, UTS healing efficiency $\left(\alpha_{\sigma U T S}\right)$, strain-to-failure healing efficiency $\left(\alpha_{\varepsilon}\right)$. Dimensions when provided, length $\mathrm{x}$ width $\mathrm{x}$ thickness $(1 \mathrm{x} \mathrm{w} \mathrm{x} \mathrm{t})$, with yarn and dog bone (DG) sample geometries indicated and gauge region detailed if specified. Cross sectional area (CSA) provided in lieu of overall/gauge dimensions where available.

\begin{tabular}{|c|c|c|c|c|c|c|c|c|c|c|c|c|}
\hline $\begin{array}{c}\text { Initial } \\
\qquad E \\
\text { [GPa] }\end{array}$ & $\begin{array}{c}\text { Initial } \\
\sigma_{U T S} \\
{[\mathrm{MPa}]}\end{array}$ & $\begin{array}{c}\text { Initial } \\
\qquad \\
{[\%]}\end{array}$ & $\begin{array}{c}\alpha_{\text {time }} \\
{[\mathbf{h}]}\end{array}$ & $\begin{array}{l}\alpha_{\text {Temp }} . \\
{\left[{ }^{\circ} \mathbf{C}\right]}\end{array}$ & $\begin{array}{c}\underset{E}{\text { Healed }} \\
{[\mathrm{GPa}]}\end{array}$ & $\begin{array}{c}\text { Healed } \\
\text { бUTS } \\
{[\mathrm{MPa}]}\end{array}$ & $\begin{array}{c}\text { Healed } \\
\varepsilon \\
{[\%]}\end{array}$ & $\begin{array}{c}\alpha_{E} \\
{[\%]}\end{array}$ & $\begin{array}{c}\alpha_{\sigma U T S} \\
{[\%]}\end{array}$ & $\begin{array}{c}\alpha_{\varepsilon} \\
{[\%]}\end{array}$ & $\begin{array}{c}\text { Dimensions } \\
\text { (Standard) } \\
{[\mathrm{mm}]}\end{array}$ & $\begin{array}{l}\text { Ref. } \\
{[\#]}\end{array}$ \\
\hline 0.269 & 10.6 & 84 & 14 & 21 & & 11.8 & 7.4 & & 111.3 & 8.8 & $3 \times 10 \times 0.25$ & 15 \\
\hline 0.261 & 3.25 & 22.5 & 0.333 & 85 & 0.150 & & & 57.5 & & & $\begin{array}{c}30.0 \times 3.3 \times \\
0.150\end{array}$ & 16 \\
\hline 0.239 & 25.0 & 138 & $0.5 / 24$ & $130 / 50$ & 0.228 & 17.0 & 50.0 & 95.4 & 68.0 & 36.2 & & 17 \\
\hline 0.209 & 7.09 & 54 & $4 / 24$ & $150 / 65$ & 0.111 & 5.21 & 30.0 & 53.3 & 73.5 & 55.6 & $\begin{array}{c}35 \times 6 \times 0.1-0.5 \\
(\mathrm{DG})\end{array}$ & 18 \\
\hline 0.141 & 11.20 & 610 & 14 & 21 & & 8.40 & 430.0 & & 75.0 & 70.5 & $3 \times 10 \times 0.25$ & 15 \\
\hline 0.075 & 0.41 & 750 & 0.083 & 25 & 0.070 & 0.40 & 750.0 & 93.3 & 97.6 & 100.0 & Yarn & 19 \\
\hline 0.066 & 5.0 & 583 & 14 & 21 & & 3.5 & 346.0 & & 70.0 & 59.3 & $3 \times 10 \times 0.25$ & 15 \\
\hline 0.036 & 3.77 & 3.1 & 24 & 25 & & 2.50 & 240.0 & & 66.3 & 7741.9 & & 20 \\
\hline 0.022 & 8.01 & 449 & $4 / 24$ & $150 / 65$ & 0.016 & 5.70 & 275.0 & 71.0 & 71.2 & 61.2 & $\begin{array}{c}35 \times 6 \times 0.1-0.5 \\
(\mathrm{DG})\end{array}$ & 18 \\
\hline 0.017 & 1.92 & 780 & 24 & 25 & & 1.75 & 720.0 & & 91.1 & 92.3 & & 20 \\
\hline 0.012 & 0.27 & 897 & 24 & 30 & & 0.29 & 817.0 & & 107.4 & 91.1 & $\begin{array}{c}20 \times 6 \times 2 \\
\text { (Gauge } 12 \times 2 \\
[1 \times w], D)\end{array}$ & 21 \\
\hline 0.011 & 4.23 & 310 & 24 & 20 & 0.011 & 2.08 & 44.0 & 99.1 & 49.2 & 14.2 & $12 \times 2 \times 1$ (D) & 22 \\
\hline 0.004 & 9.5 & 1450 & 3 & 25 & & 9.0 & 1450.0 & & 94.7 & 100.0 & $5 \times 0.5[\mathrm{w} \times 1]$ & 23 \\
\hline 0.004 & 15.2 & 1053 & 5 & 25 & & 7.0 & 700.0 & & 46.1 & 66.5 & $5 \times 0.5[\mathrm{w} \times 1]$ & 23 \\
\hline 0.0010 & & & 0.083 & 80 & 0.001 & & & 100.0 & & & $40 \times 3.5 \times 0.10$ & 24 \\
\hline 0.0009 & 3.7 & 115 & 24 & 22 & & 2.1 & 75.0 & & 56.8 & 65.2 & $\begin{array}{l}\text { ASTM D638-10 } \\
\text { (type IV) }\end{array}$ & 25 \\
\hline 0.0008 & 0.35 & 250 & 16 & 25 & & 0.35 & 230.0 & & 100.0 & 92.0 & & 26 \\
\hline
\end{tabular}


Table S8 Tensile mechanical properties of self-healing materials (continued).

\begin{tabular}{|c|c|c|c|c|c|c|c|c|c|c|c|c|}
\hline $\begin{array}{c}\text { Initial } \\
E\end{array}$ & $\begin{array}{c}\text { Initial } \\
\sigma_{U T S}\end{array}$ & $\begin{array}{c}\text { Initial } \\
\varepsilon\end{array}$ & $\alpha_{\text {time }}$ & $\alpha_{\text {Temp }}$ & $\begin{array}{l}\text { Healed } \\
\quad E\end{array}$ & $\begin{array}{c}\text { Healed } \\
\sigma_{U T S}\end{array}$ & $\begin{array}{l}\text { Healed } \\
\quad \varepsilon\end{array}$ & $\alpha_{E}$ & $\alpha_{\sigma U T S}$ & $\alpha_{\varepsilon}$ & $\begin{array}{l}\text { Dimensions } \\
\text { (Standard) }\end{array}$ & Ref. \\
\hline [GPa] & [MPa] & [\%] & [h] & {$\left[{ }^{\circ} \mathbf{C}\right]$} & [GPa] & [MPa] & [\%] & {$[\%]$} & {$[\%]$} & {$[\%]$} & [mm] & [\#] \\
\hline 0.0005 & 0.23 & 1860 & 48 & 25 & & 0.23 & 1750.0 & & 97.8 & 94.1 & $\begin{array}{l}75 \times 14 \times 1.0 \\
\text { (Gauge } 2[1])\end{array}$ & 27 \\
\hline 0.0005 & 6.4 & +200 & 0.05 & & & 0.005 & +200 & 94.1 & 97.8 & & & 28 \\
\hline 0.0003 & 1.6 & 327 & 24 & 22 & & 1.8 & & & 112.5 & & $\begin{array}{l}\text { ASTM D638-10 } \\
\text { (type IV) }\end{array}$ & 25 \\
\hline \multirow[t]{15}{*}{0.0002} & 0.13 & 827 & 28 & & & & & & & & $10 \mathrm{~mm}$ diameter & 29 \\
\hline & 4.5 & & 0.15 & 150 & & 10.0 & & & 222.2 & & $25.4 \times 10 \times 5$ & 30 \\
\hline & 4.4 & 58 & 72 & 20 & & 4.0 & 55.0 & & 90.9 & 94.8 & & 31 \\
\hline & 3.5 & 650 & 3 & 20 & & 2.8 & 525.0 & & 80.0 & 80.8 & ISO 527-3 & 32 \\
\hline & 2.1 & 700 & 24 & 25 & & 1.65 & 625.0 & & 78.6 & 89.3 & $\begin{array}{c}1 \text { [t] (Gauge } 30 \\
[1], \mathrm{DG})\end{array}$ & 33 \\
\hline & 0.9 & 165 & 120 & 20 & & 0.30 & 48.0 & & 33.3 & 29.1 & $\begin{array}{l}\text { JIS K } 7113 \text { (No. } \\
\quad 2(1 / 5))\end{array}$ & 34 \\
\hline & 0.81 & 3100 & 24 & 25 & & 0.77 & 3015.0 & & 95.1 & 97.3 & $2[\mathrm{t}](\mathrm{D})$ & 35 \\
\hline & 0.75 & 850 & 0.001 & 25 & & 0.55 & 800.0 & & 73.3 & 94.1 & & 36 \\
\hline & 0.75 & 830 & 72 & 50 & & 0.80 & 850.0 & & 106.7 & 102.4 & $\begin{array}{c}12 \times 2 \times 0.5-0.7 \\
\quad(\text { ISO } 37-4)\end{array}$ & 37 \\
\hline & 0.75 & 830 & 12 & 50 & & 0.72 & 840.0 & & 96.0 & 101.2 & $\begin{array}{l}12 \times 2 \times 0.5-0.7 \\
\quad(\text { ISO } 37-4)\end{array}$ & 37 \\
\hline & $\sim 0.7$ & 32.5 & 0.083 & 50 & & $\sim 0.8$ & 32.5 & & $<100$ & 100.0 & ASTM D638 & 38 \\
\hline & $\sim 0.5$ & 17 & 0.017 & $\sim 200$ & & $\sim 0.5$ & 17.0 & & $\sim 100$ & 100.0 & $0.325-0.400[\mathrm{t}]$ & 39 \\
\hline & 0.45 & 425 & 24 & 25 & & 0.40 & 260.0 & & 88.9 & 61.2 & ISO $527-3$ & 40 \\
\hline & 0.17 & 8 & 24 & 20 & & $\sim 0.2$ & 13.0 & & $<100$ & 162.5 & $\begin{array}{c}\mathrm{CSA} \approx 12 \mathrm{~mm}^{2} \\
\text { (D) }\end{array}$ & 41 \\
\hline & 0.06 & & 24 & & & 0.04 & & & 63.6 & & & 42 \\
\hline
\end{tabular}




\section{References}

1. Wei, L.; Ye, L., Preparation and Property of Poly(Vinyl Alcohol) Grafted with Butyl Glycidyl Ether. J. Appl. Polym. Sci. 2013, 129, 3757-3763.

2. Peppas, N. A.; Merrill, E. W., Poly(Vinyl Alcohol) Hydrogels: Reinforcement of RadiationCrosslinked Networks by Crystallization. J. Polym. Sci., Part A: Polym. Chem. 1976, 14, 441-457.

3. Amara, M. S. Nanotubes D'Imogolite et Propriétés de L'eau Confinée : Organisation, Structure et Dynamique. Thése de doctorat, Université Paris Sud, Paris XI, 2014.

4. Monet, G.; Amara, M. S.; Rouzière, S.; Paineau, E.; Chai, Z.; Elliott, J. D.; Poli, E.; Liu, L.M.; Teobaldi, G.; Launois, P., Structural Resolution of Inorganic Nanotubes with Complex Stoichiometry. Nat. Commun. 2018, 9, 2033.

5. Pichot, V.; Badaire, S.; Albouy, P. A.; Zakri, C.; Poulin, P.; Launois, P., Structural and Mechanical Properties of Single-Wall Carbon Nanotube Fibers. Phys. Rev. B 2006, 74, 245416.

6. O'Regan, D. F.; Akay, M.; Meenan, B., A Comparison of Young's Modulus Predictions in Fibre-Reinforced-Polyamide Injection Mouldings. Compos. Sci. Technol. 1999, 59, 419-427.

7. Coleman, J. N.; Cadek, M.; Blake, R.; Nicolosi, V.; Ryan, K. P.; Belton, C.; Fonseca, A.; Nagy, J. B.; Gun'ko, Y. K.; Blau, W. J., High Performance Nanotube-Reinforced Plastics: Understanding the Mechanism of Strength Increase. Adv. Funct. Mater. 2004, 14, 791-798.

8. Paineau, E.; Krapf, M.-E. M.; Amara, M.-S.; Matskova, N. V.; Dozov, I.; Rouzière, S.; Thill, A.; Launois, P.; Davidson, P., A Liquid-Crystalline Hexagonal Columnar Phase in Highly-Dilute Suspensions of Imogolite Nanotubes. Nat. Commun. 2016, 7, 10271.

9. Peijs, T.; van Vught, R. J. M.; Govaert, L. E., Mechanical Properties of Poly(Vinyl Alcohol) Fibres and Composites. Composites 1995, 26, 83-90.

10. Tucker Iii, C. L.; Liang, E., Stiffness Predictions for Unidirectional Short-Fiber Composites: Review and Evaluation. Compos. Sci. Technol. 1999, 59, 655-671.

11. Sakurada, I., Polyvinyl Alcohol Fibers. Marcel Dekker Inc: New York, U.S.A., 1985; p 435, pp 319.

12. Lourenço, M. P.; Guimarães, L.; da Silva, M. C.; de Oliveira, C.; Heine, T.; Duarte, H. A., Nanotubes with Well-Defined Structure: Single- and Double-Walled Imogolites. J. Phys. Chem. C 2014, 118, 5945-5953.

13. Yamaura, K.; Tada, M.; Tanigami, T.; Matsuzawa, S., Mechanical Properties of Films of Poly(Vinyl Alcohol) Derived from Vinyl Trifluoroacetate. J. Appl. Polym. Sci. 1986, 31, 493-500.

14. Kuraray Co. Ltd. Kuralon ${ }^{\mathrm{TM}}$ RMS702 PVA Fiber Product Information. http://kuralonfrc.kuraray.com/product-application/for-hatschek/rms702 (accessed 2020-03-10).

15. Urban, M. W.; Davydovich, D.; Yang, Y.; Demir, T.; Zhang, Y.; Casabianca, L., Key-AndLock Commodity Self-Healing Copolymers. Science 2018, 362, 220-225.

16. Fox, J.; Wie, J. J.; Greenland, B. W.; Burattini, S.; Hayes, W.; Colquhoun, H. M.; Mackay, M. E.; Rowan, S. J., High-Strength, Healable, Supramolecular Polymer Nanocomposites. JACS 2012, 134, 5362-5368.

17. Willocq, B.; Khelifa, F.; Brancart, J.; Van Assche, G.; Dubois, P.; Raquez, J. M., OneComponent Diels-Alder Based Polyurethanes: A Unique Way to Self-Heal. RSC Adv. 2017, 7, 48047-48053.

18. Li, J.; Zhang, G.; Deng, L.; Zhao, S.; Gao, Y.; Jiang, K.; Sun, R.; Wong, C., In Situ Polymerization of Mechanically Reinforced, Thermally Healable Graphene Oxide/Polyurethane Composites Based on Diels-Alder Chemistry. J. Mater. Chem. A 2014, 2, 20642-20649. 
19. Huang, Y.; Huang, Y.; Zhu, M.; Meng, W.; Pei, Z.; Liu, C.; Hu, H.; Zhi, C., MagneticAssisted, Self-Healable, Yarn-Based Supercapacitor. ACS Nano 2015, 9, 6242-6251.

20. Chen, Y.; Kushner, A. M.; Williams, G. A.; Guan, Z., Multiphase Design of Autonomic Self-Healing Thermoplastic Elastomers. Nat. Chem. 2012, 4, 467-472.

21. Chen, S.; Mahmood, N.; Beiner, M.; Binder, W. H., Self-Healing Materials from V- and HShaped Supramolecular Architectures. Angew. Chem. Int. Ed. 2015, 54, 10188-10192.

22. Amamoto, Y.; Otsuka, H.; Takahara, A.; Matyjaszewski, K., Self-Healing of Covalently Cross-Linked Polymers by Reshuffling Thiuram Disulfide Moieties in Air Under Visible Light. Adv. Mater. 2012, 24, 3975-3980.

23. Hong, G.; Zhang, H.; Lin, Y.; Chen, Y.; Xu, Y.; Weng, W.; Xia, H., Mechanoresponsive Healable Metallosupramolecular Polymers. Macromolecules 2013, 46, 8649-8656.

24. Burattini, S.; Colquhoun, H. M.; Fox, J. D.; Friedmann, D.; Greenland, B. W.; Harris, P. J. F.; Hayes, W.; Mackay, M. E.; Rowan, S. J., A Self-Repairing, Supramolecular Polymer System: Healability as a Consequence of Donor-Acceptor $\pi-\pi$ Stacking Interactions. Chem. Commun. 2009, 6717-6719.

25. Sordo, F.; Mougnier, S.-J.; Loureiro, N.; Tournilhac, F.; Michaud, V., Design of SelfHealing Supramolecular Rubbers with a Tunable Number of Chemical Cross-Links. Macromolecules 2015, 48, 4394-4402.

26. van Gemert, G. M. L.; Peeters, J. W.; Söntjens, S. H. M.; Janssen, H. M.; Bosman, A. W., Self-Healing Supramolecular Polymers in Action. Macromol. Chem. Phys. 2012, 213, 234242.

27. Li, C.-H.; Wang, C.; Keplinger, C.; Zuo, J.-L.; Jin, L.; Sun, Y.; Zheng, P.; Cao, Y.; Lissel, F.; Linder, C.; You, X.-Z.; Bao, Z., A Highly Stretchable Autonomous Self-Healing Elastomer. Nat. Chem. 2016, 8, 618-624.

28. Xu, X.; Fan, P.; Ren, J.; Cheng, Y.; Ren, J.; Zhao, J.; Song, R., Self-Healing Thermoplastic Polyurethane (TPU)/Polycaprolactone (PCL) /Multi-Wall Carbon Nanotubes (MWCNTs) Blend as Shape-Memory Composites. Compos. Sci. Technol. 2018, 168, 255-262.

29. Yu, C.; Wang, C.-F.; Chen, S., Robust Self-Healing Host-Guest Gels from Magnetocaloric Radical Polymerization. Adv. Funct. Mater. 2014, 24, 1235-1242.

30. Luo, X.; Ou, R.; Eberly, D. E.; Singhal, A.; Viratyaporn, W.; Mather, P. T., A Thermoplastic/Thermoset Blend Exhibiting Thermal Mending and Reversible Adhesion. ACS Appl. Mater. Interfaces 2009, 1, 612-620.

31. Cash, J. J.; Kubo, T.; Bapat, A. P.; Sumerlin, B. S., Room-Temperature Self-Healing Polymers Based on Dynamic-Covalent Boronic Esters. Macromolecules 2015, 48, 20982106.

32. Cordier, P.; Tournilhac, F.; Soulié-Ziakovic, C.; Leibler, L., Self-Healing and Thermoreversible Rubber from Supramolecular Assembly. Nature 2008, 451, 977.

33. An, X.; Aguirresarobe, R. H.; Irusta, L.; Ruipérez, F.; Matxain, J. M.; Pan, X.; Aramburu, N.; Mecerreyes, D.; Sardon, H.; Zhu, J., Aromatic Diselenide Crosslinkers to Enhance the Reprocessability and Self-Healing of Polyurethane Thermosets. Polym. Chem. 2017, 8, 3641-3646.

34. Zeng, C.; Seino, H.; Ren, J.; Hatanaka, K.; Yoshie, N., Self-Healing Bio-Based Furan Polymers Cross-Linked with Various Bis-Maleimides. Polymer 2013, 54, 5351-5357.

35. Rekondo, A.; Martin, R.; Ruiz de Luzuriaga, A.; Cabañero, G.; Grande, H. J.; Odriozola, I., Catalyst-Free Room-Temperature Self-Healing Elastomers Based on Aromatic Disulfide Metathesis. Mater. Horiz. 2014, 1, 237-240.

36. Sun, H.; You, X.; Jiang, Y.; Guan, G.; Fang, X.; Deng, J.; Chen, P.; Luo, Y.; Peng, H., SelfHealable Electrically Conducting Wires for Wearable Microelectronics. Angew. Chem. Int. Ed. 2014, 53, 9526-9531. 
37. Imato, K.; Takahara, A.; Otsuka, H., Self-Healing of a Cross-Linked Polymer with Dynamic Covalent Linkages at Mild Temperature and Evaluation at Macroscopic and Molecular Levels. Macromolecules 2015, 48, 5632-5639.

38. Tee, B. C. K.; Wang, C.; Allen, R.; Bao, Z., An Electrically and Mechanically Self-Healing Composite with Pressure- and Flexion-Sensitive Properties for Electronic Skin Applications. Nat. Nanotechnol. 2012, 7, 825.

39. Burnworth, M.; Tang, L.; Kumpfer, J. R.; Duncan, A. J.; Beyer, F. L.; Fiore, G. L.; Rowan, S. J.; Weder, C., Optically Healable Supramolecular Polymers. Nature 2011, 472, 334.

40. Zhang, A.; Yang, L.; Lin, Y.; Yan, L.; Lu, H.; Wang, L., Self-Healing Supramolecular Elastomers Based on the Multi-Hydrogen Bonding of Low-Molecular Polydimethylsiloxanes: Synthesis and Characterization. J. Appl. Polym. Sci. 2013, 129, 2435-2442.

41. D'Elia, E.; Barg, S.; Ni, N.; Rocha, V. G.; Saiz, E., Self-Healing Graphene-Based Composites with Sensing Capabilities. Adv. Mater. 2015, 27, 4788-4794.

42. Phadke, A.; Zhang, C.; Arman, B.; Hsu, C.-C.; Mashelkar, R. A.; Lele, A. K.; Tauber, M. J.; Arya, G.; Varghese, S., Rapid Self-Healing Hydrogels. Proc. Natl. Acad. Sci. U. S. A. 2012, $109,4383-4388$. 